\title{
Survey of medical students' knowledge and perceptions of anesthesiology at one Canadian university: pre-clerkship and during clinical clerkship, a cohort study
}

\author{
Sarah J. Henschke, BSc • Emilie M. Robertson, MD • Luke Murtha, MD • \\ Ban C. H. Tsui, MSc, MD (])
}

Received: 10 September 2017/ Accepted: 3 November 2017/Published online: 17 November 2017

(C) Canadian Anesthesiologists' Society 2017

\section{To the Editor,}

Medical schools in Canada lack a standardized curriculum for teaching anesthesiology and pain medicine. In 2014, a cohort of preclinical-year students (first and second years) at the University of Alberta ( $U$ of A) were surveyed concerning their knowledge and perceptions of anesthesiology as a specialty. ${ }^{1}$ In 2016, these same students were surveyed during their clinical attachment to examine how their knowledge as well as their interest in anesthesia as a career had changed.

After institutional ethical approval for this study was obtained, a questionnaire consisting of 14 items was developed. In 2014, responses were received from 137/165 (83\%) first-year and 132/168 (79\%) second-year students. In 2016, responses were received from 119/165 (72\%) third-year and 107/168 (64\%) fourth-year students. Figure A summarizes the students' primary sources of information about anesthesia. Among students in their clinical (third and fourth) years, 19/226 (8\%) responded that they had no learning source about anesthesia ("none") and $9(4 \%)$ reported that television was the primary source of their knowledge.

In the 2016 survey, 14/226 (6\%) clinical year students were unable to identify a simple description of how

S. J. Henschke, BSc · E. M. Robertson, MD

Department of Anesthesiology and Pain Medicine, University of Alberta, Edmonton, AB, Canada

L. Murtha, MD

Department of Radiology, University of Ottawa, Ottawa, ON, Canada

B. C. H. Tsui, MSc, MD ( $)$

Department of Anesthesiology, Perioperative and Pain Medicine, Stanford University, School of Medicine, Stanford, CA, USA

e-mail: bantsui@stanford.edu anesthesia is induced and 17/226 (8\%) were unable to describe how anesthesia is maintained. On the other hand, negative stereotypes surrounding anesthesiologists, such as professional identity, remuneration and workload decreased during the clerkship years (Figure B).

Interest in anesthesia remained high through all survey cohorts: 134/137 (98\%), 117/131 (89\%), 115/119 (97\%), and 103/107 (96\%), in first through fourth years respectively. A total of 99/268 (37\%) preclinical-year students and 114/226 (50\%) clinical-year students said they would prefer a clinical rotation, a rotation not offered at the $\mathrm{U}$ of A. Adudu et al. ${ }^{2}$ noted that $54 \%$ of students surveyed after their clinical rotation said they thought anesthesiologists were more important than they had previously believed, $17 \%$ indicated an increased interest in anesthesia as a career. Tien et al. $^{3}$ also reported increased comfort with technical skills and understanding the role of the anesthesiologist after completion of a oneweek, peer-designed elective.

In 2016, we asked U of A students "Should Canadian medical schools require a mandatory anesthesia rotation?" An affirmative response by 95/119 (80\%) third-year students and 98/107 (92\%) fourth-year students indicated that they believed knowledge of anesthesia was essential. In the absence of a mandatory rotation in anesthesia at the $\mathrm{U}$ of $\mathrm{A}$, one wonders if whether the demand for anesthesia knowledge has been satisfied or if students would further benefit by implementation of a mandatory anesthesia rotation. Hamlin et al. highlighted the relatively low levels of participation by anesthesiologists in the undergraduate curriculum across the country. ${ }^{4}$ Despite this, 2013-2016 Canadian Resident Matching Service match data showed that anesthesia was ranked as either the fourth or fifth highest first-preference residency application. Anesthesia training programs have been 
Figure Results of a cohort survey of medical students during pre-clerkship and clerkship periods from one Canadian institution. A) Primary sources of information about anesthesiology. B) Students' perceptions of anesthesiologists' role, financial compensation, and workload. C) Students' preferred methods of learning about anesthesiology.
A

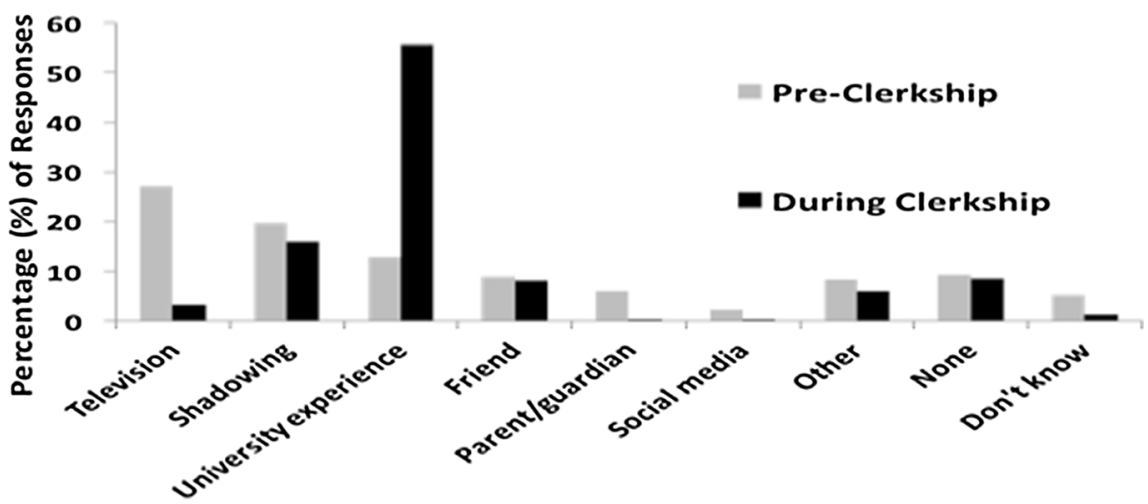

B

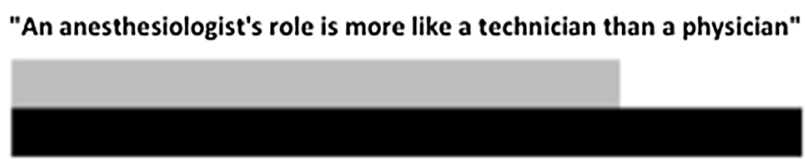

"An anesthesiologist is overpaid for the work they do compared to other medical specialties"

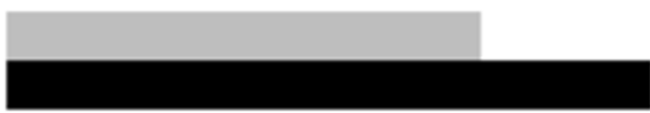

"An anesthesiologist is overworked compared to other medical specialties"

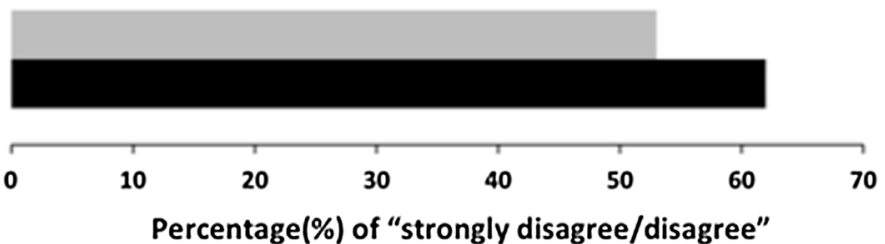

C

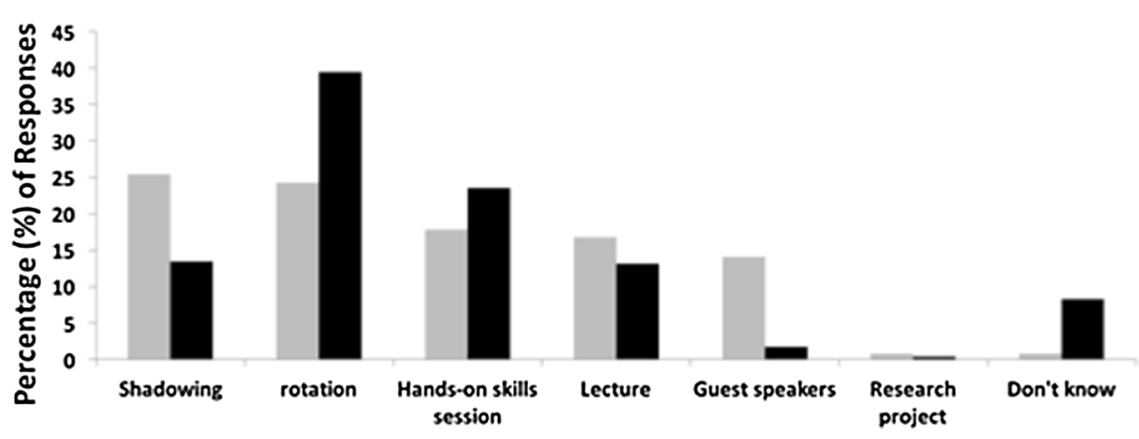

oversubscribed every year, garnering up to $5.1 \%$ of firstpreferences by CMGs and yet never offering more than $3.7 \%$ of the total residency positions. The percentage of candidates to successfully match to anesthesia as their firstchoice ranged between $71 \%$ and $78 \%$. An increased presence in the undergraduate curriculum represents an opportunity for anesthesiologists to align student interest in anesthesia and practical knowledge of our work.

Conflicts of interest None declared.

Editorial responsibility This submission was handled by Dr. Gregory L. Bryson, Deputy Editor-in-Chief, Canadian Journal of Anesthesia.

\section{References}

1. Robertson EM, Henschke SJ, Friesen J, Tsui BC. Survey of preclerkship medical students' knowledge and perceptions of anesthesiology at one Canadian university. Can J Anesth 2014; 62: $550-2$.

2. Adudu OP, Le NH, Devito I, Campbell FA, Levine MF. Medical student impressions of anesthesiology and anesthesiologists. Can J Anesth 2010; 57: 792-3.

3. Tien $M$, Aiudi CM, Sviggum HP, Long TR. A peer-designed selective in anesthesiology, critical care, and perioperative medicine for first- and second-year medical students. J Clin Anesth 2016; 31: 175-81.

4. Hamlin $C$, Bhangu $K$, Villafranca A, et al. Participation of Canadian anesthesiology departments in undergraduate medical education. Can J Anesth 2016; 64: 16-28. 